\title{
Kajian Drug Related Problems (DRPs) Terhadap Pengobatan Pasien Stroke Iskemik di Rumah Sakit Pusat Otak Nasional Jakarta Periode Januari - Desember 2015
}

\section{Study of Drug Related Problems (DRPs) to Treatment of Patient with Ischemic Stroke at National Brain Centre Hospital Jakarta Period January - December 2015}

\author{
Okpri Meila $^{1 *}$, Handika Indri Rochana ${ }^{2}$ \\ ${ }^{1}$ Fakultas Farmasi Institut Sains dan Teknologi Nasional, ${ }^{2}$ Fakultas Farmasi Universitas 17 Agustus 1945 \\ Jakarta \\ *e-mail: okprimeila@gmail.com
}

\begin{abstract}
Abstrak
Penelitian ini bertujuan untuk mengetahui persentase kejadian DRPs pada pasien stroke iskemik di Rumah Sakit Pusat Otak Nasional Jakarta. Berdasarkan data WHO tahun 2006, setiap tahun terdapat sekitar 13 juta penderita stroke baru dimana sekitar 4,4 juta diantaranya meninggal dalam 12 bulan. Saat pasien menjalani suatu pengobatan, sebagian pasien memperoleh hasil yang diharapkan yaitu sembuhnya penyakit yang diderita pasien namun tidak sedikit yang gagal dalam menjalani terapi. Oleh sebab itu, dibutuhkan konstribusi dalam mengidentifikasi, menyelesaikan dan mencegah terjadinya masalah-masalah dalam terapi obat yang disebut sebagai Drug Related Problems (DRPs). Metode yang digunakan pada penelitian ini adalah metode cross sectional dengan pengambilan data secara retrospektif. Total data sampel yang didapat sebanyak 360 sampel. Hasil penelitian menunjukkan indikasi tanpa obat sebesar 55,62\%, obat tanpa indikasi sebesar 15,17\%, interaksi obat sebesar 10,11\%, pasien gagal menerima obat sebesar 7,86\%, efek samping sebesar 6,18\% dan pemilihan obat kurang tepat sebesar 5,06\%. Data menunjukkan bahwa persentase tertinggi DRPs yaitu indikasi tanpa obat. Kata kunci: Drug Related Problems (DRPs), Stroke Iskemik, RSPON Jakarta
\end{abstract}

\begin{abstract}
This study aims to determine the percentage of DRPs of ptients with ischemic stroke at Brain Center National Hospital Jakarta. Based on data from the WHO 2006, each year there are approximately 13 million new stroke patients of which approximatelly 4,4 million of them die within 12 months. When patients undergo a treatment, most patients achieve optimal results that heal diseases suffered by patients but not least the failure in therapy. Therefore, the contribution required to identify, resolve and prevent problems in drug therapy known as Drug Related Problems (DRPs). The method used in this study is cross sectional. Total sample data obtained as many as 360 samples. The results showed indications without drugs of $55.62 \%$, drugs without indication of $15.17 \%$, drug interactions of $10.11 \%$, patients fail to receive the drug of $7.86 \%$, side effects of $6.18 \%$ and less drug selection right of $5.06 \%$. Data show that the highest percentage of DRPs are indications without drugs.
\end{abstract}

Keywords: Drug Related Problems (DRPs), Ischemic Stroke, RSPON Jakarta

\section{PENDAHULUAN}

Setiap tahunnya, 200 dari tiap 100.000 orang di Eropa menderita stroke, dan menyebabkan kematian 275.000-300.000 orang Amerika dan di pusat-pusat pelayanan neurologi Indonesia jumlah penderita gangguan peredaran darah otak (GPDO) selalu menempati urutan pertama dari seluruh penderita rawat inap (Harsono, 2007).

tiba-tiba. Setiap tahun terdapat sekitar 13 juta penderita stroke baru, dimana sekitar 4,4 juta diantaranya meninggal dalam 12 bulan (WHO, 2006). 


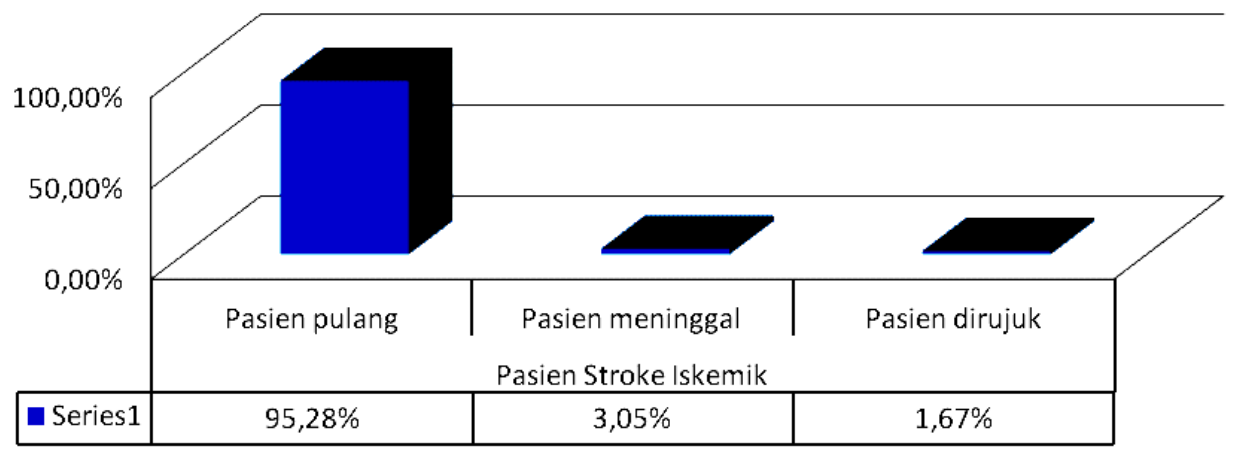

Gambar 1. Pasien Stroke Iskemik

Stroke merupakan penyakit yang memerlukan perawatan jangka panjang, sehingga untuk mendapatkan therapeutic outcome yang baik perlu kerjasama antara dokter, perawat, apoteker, pasien dan keluarga pasien. Kejadian Drug Related Problems sangat umum terjadi pada pasien rawat inap yang beresiko meningkatkan kesakitan, kematian dan biaya (Prest MS., $d k k$., 2003).Menurut WHO, stroke iskemik adalah stroke yang disebabkan penyumbatan arteri yang menyuplai darah ke otak dan terjadi secara Prediksi kedepan stroke akan meningkat menjadi 25 - 30\%, untuk mengatasinya Kementrian Kesehatan telah membangun Rumah Sakit Pusat Otak Nasional (National Brain Centre Hospital) yang merupakan salah satu rumah sakit vertikal milik Kementrian Kesehatan, terletak di jalan MT Haryono Jakarta.

Berdasarkan penelitian yang dilakukan Farizal di Rumah Sakit Stroke Nasional Bukit Tinggi mengenai DRPs pada pasien stroke di ICU didapatkan hasil bahwa hasil analisa terjadi atau tidaknya DRPs pada pasien stroke di ICU RSSN Bukittinggi selama bulan Mei 2011 sampai Juli 2011 yaitu, persentase pasien stroke yang diberikan obat tanpa indikasi medis sebesar $8,62 \%$, yang mengalami indikasi tanpa obat sebesar $27,58 \%$, ketidaktepatan pemilihan obat pada pasien stroke sebesar $15,51 \%$, yang menerima obat dengan dosis berlebih sebesar 13,79\%, yang menerima obat dengan dosis kurang sebesar 13,79\%, terjadinya reaksi efek samping obat pada pasien stroke sebesar $13,79 \%$, pasien gagal menerima obat sebesar $3,45 \%$.

\section{METODOLOGI PENELITIAN}

Penelitian dilaksanakan dengan rancangan penelitian Cross Sectional menggunakan data rekam medis.

\section{Bahan}

Semua data rekam medis pasien stroke iskemik di Rumah Sakit Pusat Otak Nasional Jakarta selama periode penelitian yang memiliki kelengkapan data.

Alat

Lembar pengumpul data, British National Formulatory (BNF) $56^{\circledR}$ tahun 2008, Drug Information Handbook tahun 2009, drug interaction checker (www.drugs.comdan www. medscape.com), Guideline Stroke.

\section{Analisa Data}

Pengumpulan data melalui pencatatan rekam medis di Rumah Sakit Pusat Otak Nasional Jakarta selama bulan Januari Desember 2015 meliputi kelengkapan data pasien (nama, umur, jenis kelamin, diagnosa, anamnesa, hasil pemeriksaan laboratorium, EEG, ECG, CT Scan, radiografi) dan profil penggunaan obat. Data yang sudah lengkap dipindahkan ke lembar pengumpul data yang telah disiapkan dan kemudian data dipindahkan ke dalam Microsoft Excel. 
Data yang diperoleh dibuat dalam sebuah tabel kemudian dilakukan analisis lebih lanjut untuk mengidentifikasi DRPs yang terjadi dan disajikan dalam bentuk tabel dan grafik.

Jenis penelitian deskriptif analitik dan data diambil secara retrospektif pada periode

\section{HASIL DAN PEMBAHASAN}

Berdasarkan 360 sampel yang memenuhi kriteria inklusi dengan cara total sampling, pada gambar 1 terdapat $6(1,67 \%)$ pasien dirujuk, $11(3,05 \%)$ pasien meninggal dan 343 $(95,28 \%)$ pasien pulang.Dimana dapat dilihat pada gambar 2, pasien mengalami stroke iskemik baru lebih besar dibandingkan stroke iskemik berulang yaitu masing-masing $66,67 \%$ dan $33,33 \%$. Umumnya pasien tidak mengetahui sejak kapan hipertensi (salah satu pencetus stroke iskemik), hal ini mungkin disebabkan perubahan pola hidup (Anies, 2006).

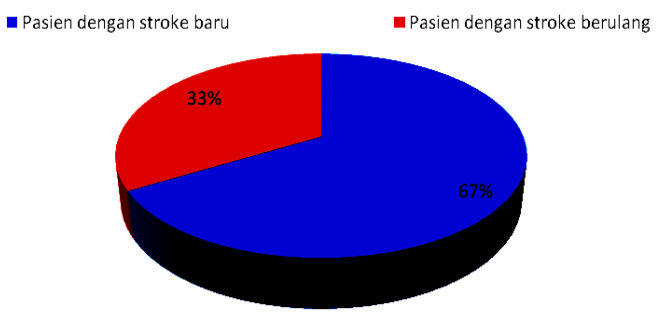

Gambar 2. Tipe Pasien Stroke Iskemik

Pada gambar 3. terlihat bahwa jumlah pasien laki-laki lebih banyak dibandingkan pasien perempuan yaitu $58,89 \%$ dan $41,11 \%$. Data ini tidak sesuai dengan data hasil Rikesdas 2013 bahwa jumlah laki-laki dan perempuan sama tinggi pada kasus stroke dengan persentase $12,0 \%$ dan $12,1 \%$. Sedangkan berdasarkan American Heart Association pada tahun 2006, penderita stroke pada laki-laki 1,25 kali lebih besar dibandingkan pada wanita.

Pada gambar 4. terlihat bahwa pasien berusia 55-64 tahun memiliki presentase sebanyak $31,94 \%$, pasien berusia 45-54 tahun dan 65-74 tahun masing-masing tahun sebesar $67 \%$ dan terendah pada umur sebanyak $24,72 \%$, pasien berusia $75+$ tahun sebanyak $9,45 \%$, pasien berusia 35-44 tahun sebanyak 7,22\%, pasien berusia 25-34 tahun sebanyak $1,67 \%$ dan pasien berusia $15-24$ tahun sebanyak $0,28 \%$, dari data tersebut dapat dilihat bahwa pasien stroke iskemik di RS Pusat Otak Nasional Jakarta paling banyak berada pada kisaran usia 55-64 tahun.

Dari gambar 5 terlihat bahwa secara garis besar penyebab masalah terkait obat tertinggi disebabkan oleh indikasi tanpa obat dengan persentase $55,62 \%$. Hal tersebut disebabkan oleh 2 penyebab yaitu, ada keluhan tetapi obat tidak diresepkan dan berdasarkan hasil data laboratorium atau data penunjang yang tidak normal tetapi obat tidak diresepkan.

Berdasarkan keluhan tetapi obat tidak diresepkan yaitu, pasien mengeluh belum buang air besar (BAB) selama 5 hari dan tidak mendapat terapi laksatif, pasien mengeluh pusing dan tidak mendapat terapi antipiretik. Dalam evidence-base medicine manajemen

Heart Association (2007) pada rekomendasi class 1 level of evidence $\mathrm{C}$ menyatakan bahwa harus diberikan antipiretik

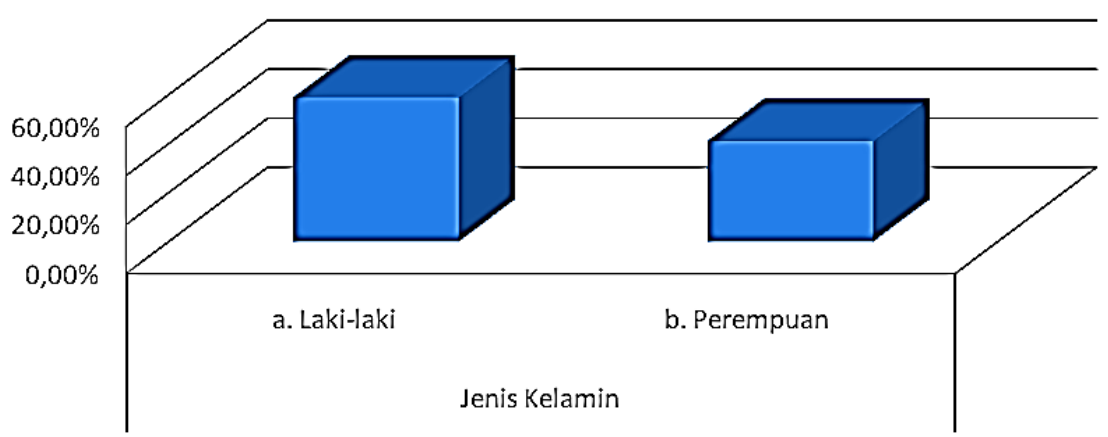

Gambar 3. Jenis Kelamin Pasien Stroke Iskemik 


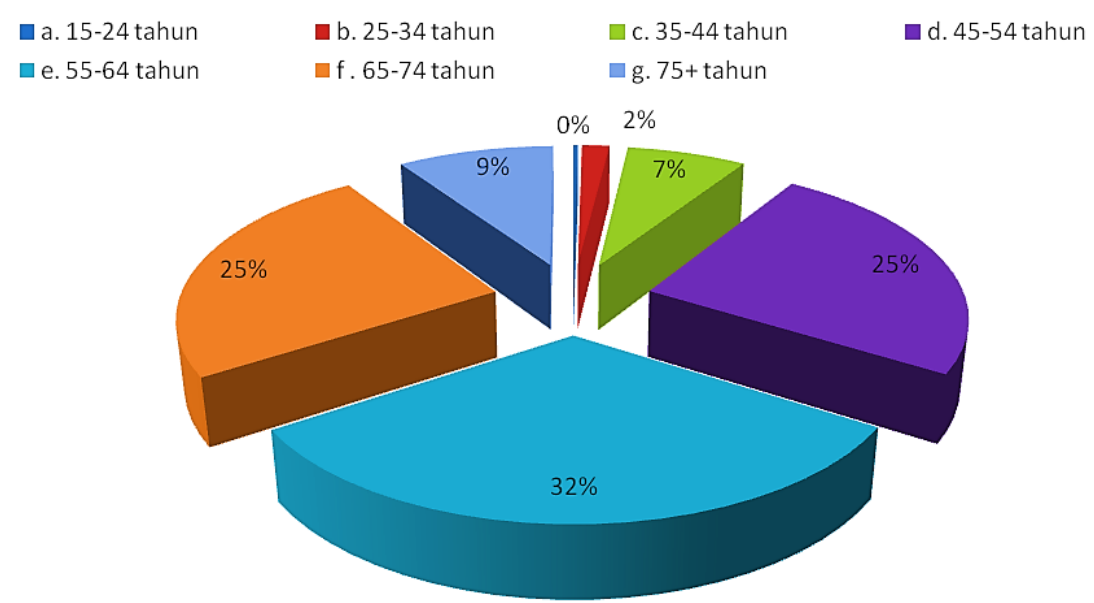

Gambar 4. Usia pasien stroke iskemik

untuk menurunkan panas.Berdasarkan hasil data laboratorium pada saat pasien masuk ke rumah sakit kadar asam urat darah menunjukkan 6,3 mg/dL, kadar albumin menunjukkan 3,2 g/dL, kadar kalium darah menunjukkan 2,9 mg/dL dan kadar SGPT dan SGOT yang tinggi tetapi tidak mendapat terapi.

Obat tanpa indikasi merupakan obat yang tidak diperlukan atau tidak sesuai dengan kondisi medis.Pada kategori ini $15,17 \%$ yang mengalami DRPs. Pasien mendapat terapi simvastatin dimana hasil kolesterol pasien normal, ini dapat beresiko menurunnya kadar kolesterol pasien. Kolesterol rendah dapat mengganggu psikologis pasien. Berdasarkan studi dari Universitas Calivornia, orangorang dengan kolesterol rendah cenderung untuk melakukan kekerasan. Penggunaan simvastatin sudah dihentikan dan pasien tidak mendapat terapi kolesterol untuk pulang.

Dua atau lebih obat yang diberikan pada waktu bersamaan dapat memberikan efek masing-masing atau saling berinteraksi. Interaksi tersebut dapat bersifat potensiasi atau antagonis satu obat oleh obat lainnya, atau kadang dapat memberikan efek yang lain. Interaksi obat yang merugikan sebaiknya dilaporkan kepada Badan/Balai/Balai Besar POM seperti halnya dengan reaksi obat merugikan lainnya. pada kategori ini terdapat $10,11 \%$ yang mengalami DRPs. Pemberian aspirin bersamaan dengan ventolin nebules. Efek aspirin akan meningkat namun efek ventolin nebules akan menurun yang akan menyebabkan sesak tidak berkurang, outcome

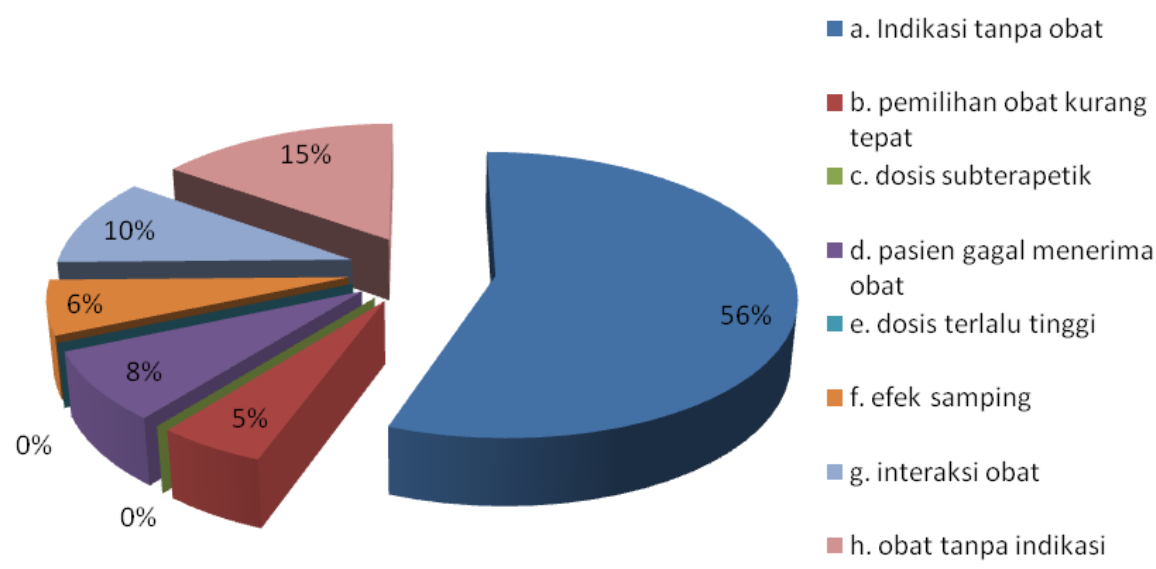

Gambar 5. DRPs (Drug Related Problems) Pasien Stroke Iskemik 
yang didapat adalah pasien masih mengeluh sesak meskipun telah diberikan ventolin nebules. Kombinasi obat yang tidak tepat dan menyebabkan interaksi yang merugikan lainnya adalah penggunaan antikoagulan secara bersamaan, seperti pradaxa dan ascardia yang keduanya mengakibatkan meningkatnya antikoagulan, aspirin dan clopidogrel yang keduanya bekerja sinergis satu sama lain, simarc dan clopidogrel yang keduanya juga bekerja sinergis satu sama lain. Penggunaan kombinasi antikoagulan bersamaan menyebabkan resiko perdarahan (hemorrhage).Kasus lainnya terjadi pada pemberian antikoagulan dan antihipertensi secara bersamaan, dimana aspirin dapat menurunkan efek valsartan, outcome yang didapat adalah tekanan darah pasien masih tinggi. Pemberian lansoprazole atau omeprazole bersamaan dengan clopidogrel dimana efek clopidogrel akan menurun dan menyebabkan infark semakin meluas.

Pada kategori pasien gagal menerima obat terdapat $7,86 \%$ yang mengalami DRPs. Masalah pasien gagal menerima obat disebabkan oleh obat yang tidak diminum atau tidak diberikan oleh perawat kepada pasien atau pemberian obat yang tidak terdokumentasi terlihat dari penelusuran data rekam medik pasien dimana pasien gagal menerima terapi amlodipin sebanyak $2 x$ selama perawatan.

Kategori efek samping terdapat sebanyak6,18\% yang mengalami DRPs. Hasil data laboratorium pasien mengalami peningkatan kadar SGPT dan SGOT setelah pemberian terapi perdipin dan seharusnya diberikan hepaprotektor untuk menurunkan kadar SGPT dan SGOT agar tidak semakin meningkat. Berdasarkan ISO volume 49, perdipin memiliki efek samping peningkatan SGOT dan SGPT. Efek samping yang sering terjadi yaitu pasien mengeluh batuk setelah mendapat terapi kaptopril, tidak semua pasien mendapat terapi mukolitik untuk mengatasi efek samping dari penggunaan terapi kaptopril, beberapa pasien ada yang dihentikan penggunaan kaptopril dan diganti dengan anti hipertensi golongan lain. Berdasarkan ISO volume 49, kaptopril memiliki efek samping batuk kering, gangguan indera pengecapan dan gatal kemerahan.

Ketidaktepatan pemilihan obat merupakan adanya pemberian obat yang tidak efektif seperti produk obat tidak efektif berdasarkan kondisi medisnya, obat bukan paling efektif untuk mengatasi penyakitnya. Kategori pemilihan obat kurang tepat terdapat sebanyak 5,06\% yang mengalami DRPs. Kadar trigliserida pasien $459 \mathrm{mg} / \mathrm{dL}$ dan mendapat terapi simvastatin tetapi kadar trigliserida pasien masih tinggi. Berdasarkan PERKI tahun 2013, Statin adalah obat penurun lipid paling efektif untuk menurunkan kolesterol LDL dan terbukti aman tanpa efek samping yang berarti. Selain berfungsi untuk menurunkan kolesterol LDL, statin juga mempunyai efek meningkatkan kolesterol HDL dan menurunkan TG.Berbagai jenis statin dapat menurunkan kolesterol LDL 18-55\%, meningkatkan koleterol HDL 5-15\% dan menurunkan TG 7$30 \%$.Sebuah analisis meta menunjukkan bahwa fibrat bermanfaat menurunkan kejadian kardiovaskular terutama jika diberikan pada pasien dengan konsentrasi TG di atas $200 \mathrm{mg} / \mathrm{dL}$ (PERKI, 2013).

\section{KESIMPULAN DAN SARAN}

Tidak semua subjek penelitian teridentifikasi mengalami DRPs, hanya 178 pasien stroke iskemik yang teridentifikasi mengalami DRPs. DRPs kategori indikasi tanpa obat sebesar 55,62\%, obat tanpa indikasi sebesar 15,17\%, interaksi obat sebesar $10,11 \%$, pasien gagal menerima obat sebesar 7,86\%, kejadian efek samping sebesar $6,18 \%$ dan mengenai pemilihan obat kurang tepat sebesar $5,06 \%$.

Penelitian yang perlu dilakukan selanjutnya adalah pemantauan secara langsung untuk mengidentifikasi adanya DRP dengan mengkaji langsung terapi yang diberikan ke pasien. Disarankan untuk penelitian selanjutnya agar dapat meneliti 
DRP dengan metode PCNE yang terbaru secara prospektif dengan penyakit serupa dan atau dengan penyakit yang lain untuk memperoleh wawasan baru.

\section{DAFTAR PUSTAKA}

Aberg, J.A., Lacy,C.F, Amstrong, L.L, Goldman, M.P, and Lance, L.L., 2009. Drug Information Handbook, 17th edition, Lexi-Comp for the American Pharmacists Association.

Anies.2006. Waspada Ancaman Penyakit Tidak Menular Solusi Pencegahan dari Aspek Perilaku dan Lingkungan.Jakarta: PT Elex Media Komputindo.

BMJ Group. 2008. British National Formulatory (BNF) $56^{\circledR}$. London: BMJ Group and the Royal Pharmaceutical Society of Great Britain.

Cipolle, R.J., Strand, L.M., Moorley P.C., 1998,Pharmaceutical care practice, McGraw-Hill Companies.Inc. New York.

Dipiro, Joseph T et al.,2008. Pharmacoterapy, A PathophysiologicApproach, $7^{\text {th }}$ Edition, Mc Graw Hill.

Farizal. 2011. Drug Related Problems (DRPs) PadaPasien Stroke di ICU (Intensive Unit Care)Rumah Sakit Stroke Nasional Bukittinggi.Padang: Program Pasca Sarjana UniversitasAndalas.

Harsono. 2007. Kapita Selekta Neurologi. Edisi ke-2. Yogyakarta: Gadjah Mada University Press, pp:86-88.

Perhimunan Dokter Spesialis Kardiovaskular Indonesia (PERKI). 2013. Pedoman Tatalaksana Dislipidemia. Edisi Kesatu. Jakarta.

Perhimpunan Dokter Spesialis Saraf Indonesia (PERDOSSI). 2011. Guideline Stroke. Jakarta.

Pharmaceutical Care Network Europe. 2010. DRP-Classification (revised 14-01-2010vm) V6.2.http://www.PCNE.org.

Prest MS., Kristanto FC., Tan CK. 2003. Reaksi Obat yang Tidak Dikehendaki, dalam Farmasi Klinis (Clinical Pharmacy), Menuju PengobatanRasional dan Penghargaan Pilihan Pasien.Elex Media Komputindo. Jakarta

Riset Kesehatan Dasar (RISKESDAS) Indonesia.Departemen Kesehatan Republik Indonesia. 2013.

Sirait, et al. 2015.Informasi Spesialite Obat (ISO) Indonesia Volume 49.Jakarta : Isfi Penerbitan. ISSN : 854-4992.

Stockley, H.I,. 2008. Stockley's Drug Interactions 8th edition. New Zealand: The Pharmaceutical Press.

World Health Organization. 2006. The WHO STEP wise Approach to Stroke Surveillance. Geneva, WHO. 